\title{
Formação continuada de professores e bibliotecários para o letramento informacional: a contribuição da educação a distância
}

\author{
Continuing education of teachers and librarians for \\ information literacy: The contribution \\ of distance education
}

\author{
Lívia Ferreira de CARVALHO' \\ Kelley Cristine Gonçalves Dias GASQUE²
}

\section{Resumo}

Na sociedade contemporânea a capacitação contínua ao longo da vida é condição para que os indivíduos possam atuar como cidadãos críticos e reflexivos. Nesse contexto, a formação continuada é fundamental para o desenvolvimento de competências e habilidades que não tenham sido aprendidas na graduação. O artigo apresenta reflexão sobre o potencial da Educação a Distância na formação continuada de professores e bibliotecários para a prática informacional, como atores fundamentais para que o letramento informacional seja implantado e consolidado na escola. Pesquisa realizada no portal da Coordenação de Aperfeiçoamento de Pessoal de Nível Superior mostra a existência de poucos trabalhos publicados sobre cursos de letramento informacional por Educação a Distância, em especial para a formação de bibliotecários.

Palavras-chave: Bibliotecários. Competência informacional. Educação a distância. Formação continuada. Professores.

\begin{abstract}
In contemporary society, continuous qualification is a condition for individuals to act as critical and reflective citizens. In this context, continuing education is essential for the development of skills and abilities that have not been learned in graduation. The article presents a reflection about the potential of Distance Education to the continuing learning of teachers and librarians for informational practice, as they are important actors for the information literacy to be implanted and consolidated in school. Research conducted on Coordenação de Aperfeiçoamento de Pessoal de Nível Superior website shows that there are few published works about information literacy courses by distance education, especially for the training of librarians.
\end{abstract}

Keywords: Librarians. Informational literacy. Distance education. Lifelong education. Teachers.

\section{Introdução}

Cada vez mais a informação e o conhecimento têm sido objeto de pesquisas, discussões e reflexões nas mais diversas áreas. A própria sociedade está em transição, passando de Sociedade da Informação para a almejada Sociedade da Aprendizagem. O que caracteriza tal sociedade não é meramente o acesso à informação, mas a

1 Universidade Federal de Goiás, Faculdade de Informação e Comunicação. Campus Samambaia, R. Samambaia, s/n., 74001-970, Goiânia, GO, Brasil. Correspondência para/Correspondence to: L.F. CARVALHO. E-mail: <liviabiblioufg@gmail.com>.

2 Universidade de Brasília, Faculdade de Ciência da Informação, Programa de Pós-Graduação em Ciência da Informação. Brasília, DF, Brasil. Recebido em 12 de agosto de 2015, reapresentado em 29 de junho de 2016 e aprovado para publicação em 13 de setembro de 2016.

Como citar este artigo/How to cite this article

Carvalho, L. F.; Gasque, K. C. G. D. Formação continuada de professores e bibliotecários para o letramento informacional: a contribuição da educação a distância. Transinformação, v. 30, n. 1, p. 107-119, 2018. https://doi.org/10.1590/2318-08892018000100009 
transformação desta última em conhecimento que possa se converter em vantagem, seja ela pessoal, competitiva ou organizacional (Pozo, 2004). As pessoas precisam ser capazes de utilizar de maneira crítica e reflexiva as informações que recebem. Isso se torna possível por meio de programas de formação e capacitação para lidar com a informação, os quais deveriam estar inseridos nas escolas, universidades, empresas e organizações que desejam melhorar o desempenho. É preciso entender que buscar e usar a informação efetivamente requer o engajamento dos sujeitos em processos de aprendizagens, e saber mediá-los torna-se condição precípua para os profissionais que lidam com a informação, como é o caso dos bibliotecários, e para os que atuam com a formação de outrem, caso dos professores.

Embora os programas de letramento informacional sejam tradicionalmente trabalhados com os mais diversos grupos de usuários, há poucos estudos que destacam a importância de professores e bibliotecários buscarem a formação continuada a fim de desenvolver a competência informacional (Vitorino, 2009).

O presente artigo constitui parte de revisão de tese de doutorado. Discute a questão da formação con-tinuada como estratégia para o desenvolvimento do letramento informacional desses dois profissionais, visto que a formação inicial na graduação parece não ser suficiente para a aquisição dos conhecimentos necessários ao entendimento dos conceitos e práticas que envolvem o tema. Destaca também a importância da Educação a Distância (EAD) como ferramenta para alcançar este propósito.

Para fins de conceituação, adota-se o entendimento de que o Letramento Informacional (LI) é o conjunto de conhecimentos e habilidades necessários ao indivíduo para buscar e usar a informação. Por sua vez, Competência Informacional refere-se ao resultado deste processo, que é a aplicação prática dos conhecimentos apreendidos para a tomada de decisões e a resolução de problemas cotidianos (Gasque, 2010).

\section{Letramento Informacional na escola}

O professor e o bibliotecário são agentes determinantes para a implantação e consolidação do movimento do letramento informacional na escola, e, portanto, requerem capacitação para que se tornem letrados informacionalmente e, consequentemente, aptos para atuarem na formação de outros. Esta capacitação dificilmente se completa em um curso de graduação, por isso a necessidade de buscar a formação continuada ao longo da vida.

Os estudos de Fialho (2004), Gasque e Tescarolo (2004), Cruz (2008), Vitorino (2008) e Orelo e Vitorino (2012), indicam a importância dos docentes e também dos bibliotecários para o desenvolvimento da competência informacional dos estudantes. Além disso, apontam a necessidade de a escola estar preparada para trabalhar o letramento informacional.

É na escola que o indivíduo começa o processo formal e a sistematizado da formação, e é também nesse ambiente que tem a oportunidade, ou deveria ter, de questionar, aprender, interagir com os conteúdos transmitidos e produzir conhecimento a partir da interpretação e reflexão. Compreende-se a educação escolar como o período composto pela educação básica (educação infantil, ensino fundamental e ensino médio) e pelo ensino superior, como consta na Lei no 9.394, de 20 de dezembro de 1996. É nesse espaço, portanto, que se deve trabalhar em prol do desenvolvimento de conhecimentos, procedimentos e atitudes para o uso da informação, uma vez que "a aquisição do capital intelectual do sujeito está diretamente ligada ao número de anos passados na escola e aos títulos adquiridos no decorrer deste período" (Mota, 2006, p.123).

Como a informação e o conhecimento são elementos produzidos em grandes quantidades na sociedade contemporânea, parece ser impossível que sejam totalmente cobertos pela educação. Por isso, mais do que transmitir informações que podem ser facilmente encontradas, os professores precisam ajudar os estudantes a desenvolver estratégias de aprendizagem necessárias para a aquisição de conhecimento. A compreensão básica dos temas, que abrangem, por exemplo, a estruturação e formulação de questões significativas sobre diversos 
tópicos, possibilita o entendimento fundamental dos princípios da aprendizagem, cruciais para a aprendizagem vitalícia. Portanto, parece imprescindível compreender que o conceito de saber significa ser capaz de encontrar informações de qualidade e saber usá-las para atingir determinados objetivos (Bransford; Brown; Cocking, 2007).

Gasque (2010) denomina letramento informacional a capacidade de buscar e usar a informação de maneira eficaz e eficiente para resolver problemas ou tomar decisões. Essa capacidade pode ser desenvolvida por meio de processo sistematizado e formal de ensino-aprendizagem desde a educação infantil. Contudo, a autora aponta que o processo de letramento informacional, fundamental para o desenvolvimento da competência, não tem sido foco da educação brasileira, em especial na educação básica. Isso acarreta problemas futuros, como estudantes que entram na graduação sem nenhuma experiência com atividades que envolvem pesquisa, por exemplo.

A inserção do letramento informacional no cotidiano de professores, bibliotecários e escola, requer entender o processo de aprendizagem como processo de descoberta, de pesquisa. De acordo com Freire (1996, p.22), "é preciso que o professor ainda em sua formação reconheça que ensinar não é transferir conhecimento, mas criar as possibilidades para a sua produção ou a sua construção". Sobre isso, ressalta-se que: "Na era da informação, o espaço de saber do docente foi dando lugar ao de mediador e problematizador do aprender: ele passou a ser visto como aquele que desafia os alunos, mostrando-Ihes, entre as várias possibilidades de aprendizagem, caminhos que poderão ser percorridos" (Cruz, 2008, p.1027).

Nesse sentido, professores precisam pensar e adotar novas estratégias que possibilitam formas de aprendizados mais significativas. O professor precisa questionar o papel e as metodologias de ensino-aprendizagem para uma educação transformadora. Para tanto, Gasque e Tescarolo (2004, p.37) argumentam sobre a necessidade de um ensino voltado para a reflexão, uma vez que, "quanto maior a capacidade de refletir, mais significativo e mais aprofundado será o pensar empregado na elaboração do conhecimento". Cruz (2008, p.1025) endossa a afirmação ao argumentar que "a capacidade reflexiva do aluno é elemento essencial para o discernimento do conhecimento, já que é ela que o torna capaz de interpretar, comparar, ponderar e integrar as informações".

De acordo com Dewey (1979), o pensamento reflexivo pode ser desenvolvido por meio de projetos de pesquisas. O referido autor vincula a aprendizagem ao processo de investigação, que, por sua vez, possibilita a reflexão. Assim, refletir é uma forma de pensar que abrange dois aspectos: (1) um estado de dúvida, incerteza, perplexidade, do qual emerge o pensamento; (2) um ato de investigação, procura e busca de informações para encontrar material que resolva o problema. Considerando a importância da pesquisa na educação básica, Fialho (2004) identificou as implicações do uso das fontes de informação na formação do pesquisador juvenil, bem como verificou a atuação do professor e da biblioteca na realização da pesquisa escolar. A autora conclui que a prática da pesquisa escolar é uma condição essencial para o desenvolvimento da competência informacional, e que a articulação entre a proposta pedagógica da escola, a influência da família, do professor, da biblioteca e dos colegas exerce papel fundamental.

A implantação de programas de letramento informacional tem suscitado muitas pesquisas. Os tópicos mais recentes abordam questões como modelos de letramento voltados para educação básica, questões curriculares (Sousa; Nascimento, 2010), Percepções Sobre Pesquisa (Kovalik; Yutzey; Piazza, 2013) e métodos de ensinoaprendizagem (Chu; Tse; Chow, 2011), dentre outros.

No que concerne ao papel dos bibliotecários e dos professores, destacam-se duas pesquisas recentes. A primeira, publicada por Varlejs, Stec e Know (2014), refere-se a um levantamento realizado em dezenove escolas secundárias para identificar o motivo dos estudantes apresentarem baixo desempenho no letramento informacional. Os bibliotecários das escolas selecionadas foram solicitados a caracterizar as relações de trabalho que mantinham com os professores, estimar o grau de competência informacional dos estudantes, bem como fornecer dados sobre os funcionários e orçamentos. Os resultados da pesquisa mostram que os fatores que mais afetam o processo de letramento informacional são a preguiça dos estudantes, a resistência dos professores em 
colaborar no processo, o desejo dos professores em assumir o controle, as concepções limitadas de letramento informacional dos professores e bibliotecários, a falta de tempo das pessoas envolvidas no processo e o fato de os bibliotecários não poderem influenciar na construção curricular. Os autores concluem que os bibliotecários escolares raramente estão em posição de colaborar de forma adequada com os professores e que as possibilidades de ajudar os estudantes no processo de letramento informacional são limitadas.

A pesquisa realizada por Smith (2013) explorou as percepções de professores secundários sobre LI e suas experiências na educação. Os resultados mostraram que houve problemas de entendimento em torno da expressão "letramento informacional", o que sugere falta de familiaridade dos participantes com o termo. Apesar de haver referências às competências no currículo escolar e documentos de apoio, os professores não compreenderam e, tampouco, souberam descrever o conjunto de habilidades necessárias ao LI. Entretanto, reconheceram a importância dos padrões de LI para os estudantes. Os professores acreditam que o desenvolvimento das competências de LI deve ser responsabilidade dos estudantes. Esses resultados sugerem que os currículos atuais são insuficientes para a formação dos aprendizes e que os professores estão efetivamente pouco preparados para essa tarefa.

Diante desses resultados fica evidente a importância do professor, da biblioteca e do bibliotecário no ambiente escolar para que os programas de letramento possam ser desenvolvidos.

\section{Formação continuada de professores e bibliotecários}

O professor e o bibliotecário são os principais responsáveis, no contexto escolar, pelo planejamento e estruturação de conteúdos e dos programas que possibilitam aos estudantes a aprendizagem dos conceitos de letramento informacional. Para tanto, é fundamental que tenham formação adequada, que muitas vezes não é obtida na graduação.

Formação é um conceito empregado para denominar tanto o processo de crescimento e amadurecimento pessoal, quanto a busca por saberes que possibilitam a constituição do fazer profissional. A formação relaciona-se à ideia de continuidade, de algo que não está completo, mas em elaboração (Almeida, 2006; Gasque; Costa, 2003).

Cruz (2008) destaca a mudança do papel do professor na era da informação, em que ele deixa de ser centralizador do conhecimento para se transformar em mediador, aquele que desafia o estudante a buscar novos caminhos, novas possibilidades de aprendizado. Ainda segundo o autor, "este papel de mediador e instigador do conhecimento, que o educador passa a assumir na era da informação, não reduz nem minimiza sua responsabilidade com a formação do sujeito, muito pelo contrário, deve contribuir para uma formação humana e ético-social" (Cruz, 2008, p.1029).

Para atender às demandas do modelo de educação centrado no estudante e na compreensão dos processos envolvidos na busca e no uso da informação, é necessário haver, na formação básica do professor, conteúdos curriculares que o capacitem a lidar eficaz e eficientemente com a informação. Uma possibilidade seria a inserção de um conjunto de disciplinas que permitisse a reflexão sobre o seu papel na construção da sociedade da aprendizagem, e que também o instruísse no desenvolvimento da própria competência informacional. Para Gasque e Tescarolo (2010), é importante destacar o papel da reflexão como elemento fundamental para o crescimento pessoal e coletivo, sendo indispensável na formação básica e continuada dos professores.

O professor comprometido com o desenvolvimento crítico dos estudantes precisa rever constantemente as metodologias de ensino para se adequar às demandas atuais da sociedade. Para tanto, ele é estimulado a buscar a formação continuada, seja para atualização, seja pela necessidade de renovação dos saberes, visto que a formação básica não propicia base adequada para a atuação profissional (Gatti, 2008). Esta formação continuada é entendida como aquela que ocorre após a graduação, sendo realizada por meio de cursos de extensão ou pós-graduação latu e stricto sensu. 
Na tentativa de minimizar os problemas informacionais que a sociedade enfrenta, Le Coadic (2004) propõe a educação para a informação. O autor acredita na criação de uma disciplina que deva ser introduzida no ensino básico, para que os conhecimentos acerca do manejo da informação sejam internalizados e aprimorados ao longo da vida:

A introdução no ensino da disciplina 'informação', com um quadro de professores especializados, seria a garantia de ingresso dos alunos na sociedade da informação. Permitiria lutar contra esse considerável analfabetismo informacional e contra um crescente iletrismo informacional, e, portanto, suprimir a distância que hoje separa os inforricos dos infopobres (Le Coadic, 2004, p.113).

A formação básica/inicial do professor e a formação continuada precisam contribuir para o desenvolvimento do letramento informacional (Belluzzo, 2004). Para desenvolver esse processo é mister que "o professor precisa se inserir em um processo de formação permanente que implica também a busca de informação para construção de novos conhecimentos" (Gasque; Costa, 2003, p.56).

Belluzzo e Kerbauy (2004, p.134) delimitam algumas medidas que as escolas precisam estabelecer para formar professores competentes em informação, quais sejam:

- A instituição deve ter compromisso com a obtenção de resultados excelentes para que os professores e estudantes aprendam a pensar criticamente, saibam solucionar problemas e desenvolvam habilidades de informação;

- os professores devem atuar de forma interdisciplinar com os profissionais atuantes nas bibliotecas das instituições, a fim de juntos promoverem programas de formação voltados ao desenvolvimento da competência em informação;

- os professores não podem preparar devidamente os estudantes para serem competentes em informação, a menos que eles mesmos compreendam como acessar e usar a informação para a produção de conhecimento;

- há necessidade de se estabelecerem padrões e indicadores de performance para que tanto os professores como os estudantes conheçam as habilidades e saibam identificá-las ao longo do processo de ensino-aprendizagem.

Transformar informação em conhecimento que possa ser aplicado no dia a dia dos estudantes torna-se um dos desafios dos educadores. É preciso criatividade, dinamicidade e capacitação adequada para que isso se concretize, uma vez que, como aponta Moran (2000), por meio das tecnologias, os dados e as informações estão à disposição de todos e, portanto, a aquisição da informação dependerá cada vez menos do professor. O papel principal do professor consiste, então, em ajudar o aprendiz a interpretar, relacionar e contextualizar os dados e informações que recebe. Rios (2010, p.52) afirma que "por intermédio do gesto de ensinar, o professor, na relação com os alunos, proporciona a eles, num exercício de mediação, o encontro com a realidade, considerando o saber que já possuem e procurando articulá-lo a novos saberes e práticas", o que demonstra a importância da postura de articulador ou mediador que o professor deve adotar.

A formação do bibliotecário geralmente é foco de discussão dos cursos de biblioteconomia, conselhos e associações de classe, pois se sabe que o perfil profissional tem se alterado ao longo dos anos. Para Vitorino (2008), há atualmente um debate sobre a formação do profissional da informação nunca antes visto. Com as mudanças sociais e tecnológicas, foi preciso que o profissional se adaptasse e passasse a oferecer serviços e produtos adequados às novas demandas dos usuários, que estão se tornando cada vez mais autônomos nos processos de busca por informações, mas nem sempre sabem identificar o que é relevante. Nesse sentido, o bibliotecário desempenha atividades semelhantes àquelas desenvolvidas pelos professores, por se preocupar, segundo Mueller (1989, p.64), "não em fornecer informação propriamente dita, mas orientar pessoas na aquisição de conhecimentos e prepará-las para que possam sozinhas, buscar informações sempre que precisarem". O bibliotecário tem a função de educar, mostrar o caminho para a resolução de problemas a partir do uso consciente da informação. 
A atuação em parceria com os professores, voltada para o letramento informacional, muitas vezes deixa de ocorrer devido à falta de preparo do profissional, pois os currículos dos cursos de biblioteconomia, em sua maioria, não contemplam conteúdos pedagógicos fundamentais para esse trabalho. Mata e Casarin (2012) apontam que não necessariamente, por se formar em biblioteconomia, o graduando sairá da universidade competente em informação, pois há pesquisas que apontam os deficit na formação do profissional. As autoras evidenciam ainda que há preocupação em nível mundial com os currículos dos cursos de biblioteconomia, atentando para a inserção dos conteúdos relativos à competência informacional.

Campello (2009) aponta que no contexto escolar os bibliotecários empreendem maior esforço nas atividades de promoção da leitura, e menos nas de instrução à pesquisa escolar, o que indica que as práticas para a consolidação do letramento informacional no Brasil ainda estão aquém das ações necessárias. De acordo com Santos (2011), o bibliotecário deve assumir postura de liderança, atuando em conjunto com outros profissionais e sendo proativo, buscando sempre a democratização do acesso à informação. Além disso, é preciso evidenciar o que uma biblioteca faz, quais serviços oferece, para quê serve e em que medida pode auxiliar a comunidade escolar e também aquela a que pertence. Dudziak (2003, p.31) aponta que "o desenvolvimento de programas educacionais voltados para a information literacy se faz a partir de uma mudança de filosofia de educação, não mera inclusão de atividades que objetivem a habilitação em certas atividades ligadas à informação".

Com o propósito de capacitar os bibliotecários em relação à competência informacional, a oferta de cursos de formação continuada tem crescido, tanto por parte de associações de classe quanto pelas escolas de biblioteconomia e ciência da informação (Mata; Casarin, 2012). Isso pode ser um indicador de que os profissionais demandam por novos conhecimentos, e, em contrapartida, o mercado oferece capacitação para suprir essa demanda.

É fundamental que o bibliotecário se conscientize do seu papel de educador e se capacite para exercer ações dessa natureza, de modo a auxiliar no desenvolvimento do letramento informacional. A formação acadêmica não é suficiente para desenvolver as competências necessárias ao profissional. Por isso, é preciso investir em educação continuada e integrá-la à história de vida do profissional para que seja efetiva, observando os aspectos culturais, profissionais, políticos e sociais envolvidos no processo (Farias; Vitorino, 2009; Vitorino, 2008).

\section{A Educação a Distância como estratégia para a formação continuada em Letramento Informacional}

A Educação a Distância desenvolveu-se muito nos últimos anos. Um dos principais motivos refere-se ao uso das Tecnologias da Informação e Comunicação (TIC), que possibilitaram a criação de plataformas didáticas online, as quais permitem manter relação mais próxima e dinâmica com o estudante, bem como auxiliam diretamente a produção de materiais didáticos multimídias mais interativos. A EAD pode ser caracterizada como modalidade de ensino alternativa, que permite que pessoas residentes em áreas isoladas ou com acesso limitado à educação possam estudar. Em seus primórdios era realizada via correio, transmitindo as informações e instruções para os estudantes e recebendo destes as respostas das atividades desenvolvidas (Almeida, 2003).

Com a evolução das tecnologias e sua utilização na EAD, foi possível a expansão bem como o maior alcance e agilidade no contato com os estudantes. Atualmente, o modelo utilizado pressupõe a disponibilização de um Ambiente Virtual de Aprendizagem (AVA); tutores para interagirem com o estudante e o ambiente; professores para desenvolvimento dos materiais didáticos e instrucionais; pessoal técnico e de apoio; e materiais didáticos para estudo, sejam no formato de livro, apostilas, CD-ROM ou outros objetos de aprendizagem. De acordo com Almeida (2003), o problema dessa abordagem consiste na ausência de envolvimento do professor, na maioria das vezes, com o estudante, pois a interação fica a cargo do tutor. Por sua vez, o tutor nem sempre conhece adequadamente o conteúdo e, se não estiver preparado para a atividade, pode tornar a relação com o aprendiz superficial e causar desinteresse por parte dele. 
Enquanto no ensino presencial, em geral, o processo se centra no professor, na EAD ele se centra no estudante, o que possibilita outro olhar sobre os materiais didáticos e sobre a aprendizagem: esta é mais autônoma, uma vez que "os estudantes precisam assumir a responsabilidade pelo próprio estudo, decidindo quanto tempo, em qual intensidade e em que momento realizarão as tarefas" (Costa; Franco, 2005, p.5).

Para Martins, "Diferentemente da compreensão adotada pela visão tradicional que concebia o tempo fora da temporalidade de um sujeito real, a Educação a Distância possui uma compreensão de que o tempo é de cada sujeito de aprendizagem e exige uma pedagogia diferenciada" (Martins, 2008, p.361).

O fato de a EAD ter outra perspectiva sobre o tempo e espaço permite que o planejamento das atividades se centre em estratégias individuais para que cada estudante construa o aprendizado no próprio ritmo. Dentre essas possibilidades, destaca-se o potencial dos AVA para melhorar a interação do estudante com o conhecimento, permitindo aprendizado mais significativo. No ambiente virtual, ele interage com outros estudantes por meio de chats e fóruns, o que amplia sua visão sobre o assunto discutido e agrega valor ao estoque de conhecimentos. Para tanto, a qualidade do material disponibilizado para estudo e a capacidade do tutor de mediar o debate são elementos fundamentais. Conforme Martins (2008), a melhoria da qualidade dos cursos ofertados a distância relaciona-se ao investimento, principalmente, na formação dos docentes e tutores.

No Brasil, a educação a distância é regida pela Lei de Diretrizes e Bases da Educação Nacional (Lei no 9 394/96), e regulada por várias outras normas: Decreto n 5 622, de 19 de dezembro de 2005; Decreto no 5 773, de 9 de maio de 2006; Decreto no 6303, de 12 de dezembro de 2007; e Portaria Normativa no 40, de 12 de dezembro de 2007. Os referenciais de qualidade para EAD, com a primeira versão publicada em 2003 e, em 2007, a versão preliminar, embora não tenham força de lei, podem atuar como norteadores para subsidiar atos legais do poder público em relação aos processos específicos de regulação, supervisão e avaliação dessa modalidade.

Os referenciais de qualidade para EAD em 2007 deixam explícitas as diferentes possibilidades de estrutura dos programas, endossando que se deve considerar em primeiro lugar a educação, antes de se pensar no modo de organização: à distância. Além disso, destacam a necessidade da abordagem sistêmica, que envolve aspectos pedagógicos, recursos humanos e infraestrutura. Essas dimensões devem estar expressas no Projeto Político-Pedagógico do curso a partir da descrição dos seguintes tópicos: (i) Concepção de educação e currículo no processo de ensino-aprendizagem; (ii) Sistemas de Comunicação; (iii) Material didático; (iv) Avaliação; (v) Equipe multidisciplinar; (vi) Infraestrutura de apoio; (vii) Gestão Acadêmico-Administrativa e (viii) Sustentabilidade financeira.

Em pesquisa realizada sobre cursos de educação continuada de bibliotecários na área de letramento informacional, a EAD constitui o principal meio utilizado no Brasil. É o caso do curso intitulado Competência em Informação (http://febab.org.br/?page_id=838) ofertado em 2014 pela Federação Brasileira de Associações de Bibliotecários, Cientistas da Informação e Instituições. O curso foi realizado na modalidade à distância com carga horária de cinquenta horas, ministrado pela professora Dudziak, com vagas apenas para bibliotecários.

A Universidade Federal do Ceará promoveu, no mês de maio de 2015, um curso (http://www.ufc.br/ noticias/noticias-de-2015/6638-inscricoes-abertas-para-curso-de-competencia-em-informacao-para-servidores) de 32 horas, intitulado "Desenvolvimento da competência em informação no contexto universitário", destinado aos servidores técnico-administrativos e docentes da instituição. O objetivo foi aprimorar conhecimentos e habilidades relacionados ao acesso e uso da informação.

A empresa MMH Informação (http///wnw.mmhinformacao.com.br/pg/cursos.php?detalhe=sim\&id_curso=13) ofertou, de maio a junho de 2015, o curso "Competência em informação para gestores do conhecimento nas organizações", coordenado pela professora Belluzzo. Teve como público-alvo profissionais de diversas áreas, que atuam com informação e conhecimento como fatores estratégicos nas organizações.

A iniciativa considerada mais abrangente é a de um grupo de docentes da Universidade Federal de Goiás, que estruturou o Curso de Especialização a distância intitulado "Letramento Informacional: educação para 
a informação" - CELI. O curso (http://celi.ciar.ufg.br/) teve como objetivo principal 'contribuir para a promoção, no âmbito escolar, de educação voltada para a informação, observando-se os aspectos técnicos, éticos, legais e pedagógicos envolvidos na prática informacional, de forma articulada à proposta pedagógica e à concepção de uma aprendizagem contínua e autônoma' em 2014.

A estrutura pedagógica do curso foi baseada nas quatro dimensões da competência informacional, sugeridas por Orelo e Vitorino (2012) e Vitorino e Piantola (2011). As dimensões são a política, a ética, a estética e a técnica, que englobam as várias atitudes que devem ser desenvolvidas por um indivíduo competente em informação. (Vitorino; Piantola, 2011).

Esse curso pode ser considerado iniciativa pioneira na área de Letramento Informacional no Brasil, por ser especialização latu sensu gratuita, financiada por meio de edital da Universidade Aberta do Brasil (UAB)/Fundação da Coordenação de Aperfeiçoamento de Pessoal de Nível Superior (Capes), e ofertada também para professores.

Pesquisa realizada em julho de 2015 no Google Acadêmico com as palavras-chave"letramento informacional/ competência informacional" e "educação a distância" recuperou dois artigos publicados no Brasil, que integram esses dois temas. No primeiro artigo, Vitorino (2009) discorre sobre a aprendizagem contínua, a "presencialidade", a flexibilidade, a "distancialidade", a alfabetização digital e a interação como elementos possíveis na construção do conhecimento na modalidade à distância. Afirma que a competência informacional na EAD torna-se fundamental para a construção do conhecimento. No segundo artigo, Gomes, Fialho e Silva (2013) analisam a competência informacional dos agentes envolvidos no ensino a distância da Universidade Federal de Goiás, considerando como agentes os coordenadores, os tutores e os auxiliares de biblioteca. Os dados mostram que os participantes da pesquisa se declararam competentes na maioria dos padrões estabelecidos pela Association of College and Research Libraries (ACLR), exceto naqueles que dizem respeito ao acesso eficiente da informação (padrão 2) e à compreensão das dimensões econômica, legal e social que permeiam o uso da informação (padrão 5).

Em julho de 2015, foi realizado levantamento bibliográfico no portal da Capes, com os descritores "distance education" and "information literacy", com a recuperação de 606 resultados. Desses, 168 foram artigos de periódicos revisados por pares. Em seguida, esse resultado foi refinado por data de publicação, considerando-se somente os artigos publicados entre 2010 e 2015, em um total de 63. Entretanto, a análise item a item mostrou grande número de artigos repetidos, artigos sem integração dos dois temas e, por fim, itens fora do formato estipulado, como, por exemplo, resenhas e recursos textuais, dentre outros. Por fim, foram analisados 14 artigos. Em cada um deles, foram identificados o tema de pesquisa, o sujeito, as conclusões principais e a autoria, como se observa no Quadro 1. O objetivo é apresentar o panorama das pesquisas publicadas sobre o assunto nos últimos cinco anos.

Esses temas de pesquisa foram classificados em quatro categorias, quais sejam: fundamentos de ensino-aprendizagem; ferramentas de EAD; competências do bibliotecário; e avaliação e planejamento, como apresentado no Quadro 2.

A análise dos artigos publicados nos últimos cinco anos no portal da Capes mostra, grosso modo, poucas pesquisas sobre cursos de letramento informacional na modalidade de EAD, bem como a ausência de artigos que tratam de cursos de EAD para formação dos bibliotecários em LI. Isso parece um parodoxo, em especial, pelo esforço na conscientização sobre a importância do letramento informacional na sociedade contemporânea, bem como sobre a importância dos bibliotecários em assumir essa missão. Sobre isso, Vitorino (2008, p.6) afirma que "é imprescindível nos dias atuais tratar da educação contínua ou permanente, ou ainda, da formação para toda a vida (lifelong learning) - de Profissionais da Informação, seja de forma presencial, seja na modalidade da Educação a Distância (EAD)". Observa-se também a necessidade de discutir a questão das competências necessárias aos bibliotecários para mediar cursos de LI em EAD. Os fundamentos de ensino-aprendizagem e as ferramentas de EAD foram as categorias mais exploradas, o que demonstra a importância dessas questões para a implementação e consolidação de programas de LI, pois, como Gasque e Tescarolo (2010) afirma, o LI precisa ser compreendido como processo de aprendizagem para o desenvolvimento das competências informacionais. 
Quadro 1. Pesquisas publicadas entre 2010/2015 com os temas LI e EAD.

\begin{tabular}{ll}
\hline Tema de pesquisa & \multicolumn{1}{c}{ Objeto } \\
\hline $\begin{array}{l}\text { Aprendizagem situada em cursos de LI } \\
\text { a distância. }\end{array}$ & \\
Uso dos recursos de bibliotecas di- & 3517 estudantes de \\
gitais e autoeficácia em curso de LI a & EAD.
\end{tabular}
distância.

Aprendizagem baseada em problemas em módulo de LI a distância.

Modelo contextual de LI a distância Relato. surgido a partir da disciplina de sistema de informação geográica (GIS).

Visão holística em cursos de LI a distância.

Revisão analítica da literatura.

Screencasting (captura de ações em uma tela de computador, com o objetivo de mostrar aos outros como realizar tarefas em um site ou em um determinado ambiente de software) como ferramenta de ensino de LI.

Projeto piloto com uso do Skype.

Relações entre avaliação crítica de informações online, como uma medida de letramento informacional, e componentes do letramento midiático.

Estratégias de aprendizagem e fatores motivacionais.

Webconferência para cursos de LI a Estudantes de pósdistância.

Análise de artigos de pesquisa e artigos de opinião dos estudantes.

.

103 professores.

Revisão de literatura e descrição do projeto pelos autores.

Estudantes de graduação.

119 e-formandos. Estudantes de pós-

A APB foi eficaz para alguns estudantes, mas não para todos. Metade dos estudantes se engajou nas questões mais aprofundadamente e apresentou estratégias de avaliação mais sofisticadas e pensamento metacognitivo.

A junção dos dois programas possibilitou um conjunto de competências transferíveis, como facilitador para a aprendizagem independente.

Baseando-se em estudo contextual de Nazari de LI em um programa de ensino à distância online de 2011, propõe uma forma holística de ver e praticar LI em ambientes eletrônicos, alinhada com as origens do LI. Essa abordagem permite que o e-estudante de LI conceitue e personalize o seu estilo de aprendizagem.

A maioria das reações dos participantes com os screencasts informais do bibliotecário foi positiva ou muito positiva, mas muitos participantes ainda preferem receber as respostas para as perguntas por e-mail.

Skype tem limitações como ferramenta para formação; no entanto, mostrou ser efetivo no "primeiro passo" para a formação a distância.

Os resultados sugerem relação significativa e positiva entre esses letramentos. Esses achados sugerem uma variedade de tipos de estratégias que instrutores e designers instrucionais podem empregar para o desenvolvimento de competências de letramento informacional.

A metacognição, a gestão do esforço, a elaboração de estratégias de pensamento crítico, bem como a crença no controle se relacionam a diferentes dimensões de autoeficácia do LI.

Devido às limitações da tecnologia, houve redução na quantidade de informação fornecida simultaneamente aos estudantes. A comunicação clara com os usuários (estudantes e professores) é a chave para qualquer programa bem-sucedido de formação, independentemente de ser presencial ou a distância.

Embora o tutorial tenha sido bem aceito pelos estudantes, houve necessidade de reforçar o conteúdo de ensino. tudantes e avaliação das estratégias de busca finais.
1 de 2
Nazari e

Webber

(2012)

Bailey (2012)

Heather e Nicole (2011)

Van De Vord

(2010)

Kilik-Cakmac

(2010)

Barnhart e Stanfield

(2011)

Boden e

Murphy

(2012)

Tutorial com uso de
ensino de LI a distância. 
Quadro 1. Pesquisas publicadas entre 2010/2015 com os temas LI e EAD.

\begin{tabular}{|c|c|c|c|}
\hline Tema de pesquisa & Objeto & Conclusão & Autoria \\
\hline $\begin{array}{l}\text { Fundamentos de e-learning para } \\
\text { cursos de LI a distância. }\end{array}$ & Revisão de literatura. & $\begin{array}{l}\text { As bibliotecas são o coração das instituições e, portanto, } \\
\text { estão destinadas a desempenhar papel vital nas atividades } \\
\text { de aprendizagem, bem como a apoiar todos os tipos de } \\
\text { aprendizagem, o que inclui o e-learning. Há necessidade de } \\
\text { formação para os bibliotecários adotarem as tecnologias de } \\
\text { e-learning e colaborarem com faculdades e departamentos } \\
\text { como tutores dos estudantes. }\end{array}$ & Eke (2010) \\
\hline $\begin{array}{l}\text { Bibliotecários atuantes em EAD: } \\
\text { estudo de caso dos anúncios de } \\
\text { empregos. }\end{array}$ & $\begin{array}{l}\text { Anúncios de empre- } \\
\text { gos. }\end{array}$ & $\begin{array}{l}\text { Competências tecnológicas, conhecimento em ciência da } \\
\text { informação e comunicação são fundamentais para os bibliote- } \\
\text { cários trabalharem em EAD. }\end{array}$ & Tang (2013) \\
\hline $\begin{array}{l}\text { Avaliação do curso de Ll a distância } \\
\text { para estudantes de medicina. }\end{array}$ & $\begin{array}{l}\text { Estudantes de medi- } \\
\text { cina que se inscreve- } \\
\text { ram no curso entre o } \\
\text { outono de } 2008 \text { e o } \\
\text { outono de } 2010 \text {. }\end{array}$ & $\begin{array}{l}\text { Pontos positivos do curso: tempo e flexibilidade do espaço, } \\
\text { estudo no próprio ritmo e tutoriais interativos online. A maioria } \\
\text { dos alunos estavam satisfeitos com os tópicos ensinados } \\
\text { como metodologia de busca na base de dados Web of Science, } \\
\text { Scopus e databases médicos, uso do End Note Web e estilo de } \\
\text { citação ISO 690. A maioria das tarefas, como busca nas bases de } \\
\text { dados online ou encontrar o fator de impacto de uma revista, } \\
\text { foi avaliada como benéfica. }\end{array}$ & $\begin{array}{l}\text { Kratochvil } \\
\text { (2013) }\end{array}$ \\
\hline
\end{tabular}

Nota: LI: Letramento Informacional; EAD: Educação a Distância.

Fonte: Elaborada pelas autoras (2015) a partir dos dados encontrados no portal da Coordenação de Aperfeiçoamento de Pessoal de Nível Superior.

Quadro 2. Categorias dos temas de pesquisas publicadas entre 2010/2015 sobre LI e EAD.

\begin{tabular}{ll}
\hline Categorias & Tema de pesquisa \\
\hline Fundamentos de ensino-aprendizagem. & Aprendizagem situada em cursos de LI a distância. \\
& Aprendizagem baseada em problemas em módulo de LI a distância. \\
& Estratégias de aprendizagem e fatores motivacionais. \\
& Fundamentos de e-learning para cursos de LI a distância. \\
& Modelo contextual de LI a distância, surgido a partir da disciplina de sistema de informação \\
& geográfica. \\
& Uso dos recursos de bibliotecas digitais e autoeficácia em curso de LI a distância. \\
& Screencasting como ferramenta de ensino de LI. \\
& Projeto piloto com uso do Skype. \\
& Webconferência para cursos de LI a distância. \\
& Tutorial com uso de screencast para ensino de LI a distância. \\
& Bibliotecários atuantes em EAD: estudo de caso dos anúncios de empregos. \\
& Visão holística em cursos de LI a distância. \\
Competências do bibliotecário. & Relações entre avaliação crítica de informações online, como uma medida de letramento \\
Avaliação e planejamento. & informacional, e componentes do letramento mediático. \\
Avaliação do curso de LI a distância para estudantes de medicina.
\end{tabular}

Nota: LI: Letramento Informacional; EAD: Educação a Distância.

Fonte: Elaborado pelas autoras (2015). 
As iniciativas promovidas no Brasil em relação à capacitação em letramento informacional demonstram preocupação com a formação continuada dos profissionais que lidam com a informação no cotidiano ou que exercem cargos de gerência nas organizações. Não é mais atribuição apenas dos bibliotecários organizar e tratar as informações; vários profissionais das mais diversas áreas têm se envolvido nessa tarefa, e para tanto é preciso que tenham o conhecimento necessário. Contudo, essas iniciativas precisam ser mais intensificadas.

A Educação a Distância é a ferramenta mais utilizada para oferecer cursos de educação continuada nessa área, porém falta contemplar alguns conteúdos básicos para a formação em letramento informacional, que na maioria das vezes centra-se na dimensão técnica, que diz respeito à busca e ao uso da informação. Porém, o letramento informacional envolve, além dessa dimensão, o pensamento reflexivo e as questões relacionadas à ética da informação, que são fundamentais para a cidadania.

A sociedade da aprendizagem requer das pessoas habilidades para lidar com a informação, transformando-a em conhecimento e aprendizado ao longo da vida, de forma a melhorar a vida pessoal e da coletividade. Isso se torna possível por meio da educação. É fundamental que professores e bibliotecários, inseridos no ambiente escolar, tenham capacitação adequada para atuarem como multiplicadores, auxiliando na promoção de programas de letramento informacional na escola e contribuindo para a construção de uma sociedade mais crítica, reflexiva e justa.

Por fim, vale destacar, ao considerar a quantidade de artigos publicados nos últimos cinco anos, que esse assunto ainda não se tornou tema de pesquisa de grande interesse. Os resultados mostram que há muito campo para pesquisa e muitos investimentos a serem realizados na área.

\section{Colaboradores}

Todos os autores contribuíram na concepção e desenho do estudo, análise de dados e redação final.

\section{Referências}

Almeida, M. E. B. Educação a distância na internet: abordagens e contribuições dos ambientes digitais de aprendizagem. Educação e Pesquisa, v. 29, n. 2, p. 327-340, 2003.

Almeida, M. I. Apontamentos a respeito da formação de professores. In: Barbosa, R. L. L. Formação de educadores: artes e técnicas, ciências e políticas. São Paulo: Editora Unesp, 2006. p. 177-188.

Bailey, J. Informal screencasting: Results of a customersatisfaction survey with a convenience sample. New Library World, v. 113, n. 1/2, p. 7-26, 2012.

Barnhart, A. C.; Stanfield, A. G. When coming to campus is not an option: Using web conferencing to deliver library instruction. Reference Services Review, v. 39, n. 1, p. 58-65, 2011.

Belluzzo, R. C. B. Formação contínua de professores do ensino fundamental sob a ótica do desenvolvimento da information literacy, competência indispensável ao acesso à informação e geração do conhecimento. Transinformação, v. 16, n. 1, p. 17-32, 2004.

Belluzzo, R. C. B.; Kerbauy, M. T. M. Em busca de parâmetros de avaliação da formação contínua de professores do ensino fundamental para o desenvolvimento da information literacy. Educação Temática Digital, v. 5, n. 2, p. 129-139, 2004.

Boden, C.; Murphy, S. The latent curriculum: Breaking conceptual barriers to information architecture. The Canadian Journal of Library and Information Practice and Research, v. 7, n. 1, p. 1-10, 2012.

Bransford, J. D.; Brown, A. L.; Cocking, R. R. (Org.). Como as pessoas aprendem. São Paulo: Senac, 2007.

Campello, B. S. Letramento informacional no Brasil: práticas educativas de bibliotecários em escolas de ensino básico. 2009. 208 f. Tese (Doutorado em Ciência da Informação) Universidade Federal de Minas Gerais, Belo Horizonte, 2009.

Catalano, A. The Effect of a Situated Learning Environment in a distance education information literacy course. The Journal of Academic Librarianship, v. 41, n. 5, p. 653-659, 2015.

Chu, S.; Tse, S.; Chow, K. Using collaborative teaching and inquiry project-based learning to help primary school students develop literacy and information skills. Library and Information Science Research, v. 32, n. 2, p. 132-143, 2011. 
Costa, L. A. C.; Franco, S. R. K. Ambientes virtuais de aprendizagem e suas possibilidades construtivistas. Novas Tecnologias na Educação, v. 3, n. 1, p. 1-10, 2005.

Cruz, J. M. O. Processo de ensino-aprendizagem na sociedade da informação. Educação de Sociedade, v. 29, n. 105, p. 1023-1042, 2008.

Dewey, J. Como pensamos: como se relaciona o pensamento reflexivo com o processo educativo: uma reexposição. 4. ed. São Paulo: Nacional, 1979.

Diekema, A. R.; Holliday, W.; Leary, H. Re-framing information literacy: Problem-based learning as informed learning. Library and Information Science Research, v. 33, n. 4, p. 261-268, 2011.

Dudziak, C. A. Information literacy: princípios, filosofia e prática. Ciência da Informação, v. 32, n. 1, p. 23-35, 2003.

Eke, $H$. N. The perspective of e-learning and libraries in Africa: Challenges and opportunities. Library Review, v. 59, n. 4, p.274290, 2010.

Farias, C. M.; Vitorino, E. V. Competência informacional e dimensões da competência do bibliotecário no contexto escolar. Perspectivas em Ciência da Informação, v. 14, n. 2, p. 2-16, 2009.

Fialho, J. F. A formação do pesquisador juvenil: um estudo sob o enfoque da competência informacional. 2004. $131 \mathrm{f}$. Dissertação (Mestrado em Ciência da Informação) - Universidade Federal de Minas Gerais, Belo Horizonte, 2004.

Freire, P. Pedagogia da autonomia: saberes necessários à prática educativa. 35. ed. São Paulo: Paz e Terra, 1996.

Gasque, K. C. G. D. Arcabouço conceitual do letramento informacional. Ciência da Informação, v. 39, n. 3, p .83-92, 2010.

Gasque, K. C. G. D.; Costa, S. M. S. Comportamento dos professores da educação básica na busca da informação para a formação continuada. Ciência da Informação, v. 32, n. 3, p. 54-61, 2003.

Gasque, K. C. G. D.; Tescarolo, R. Sociedade da aprendizagem: informação, reflexão e ética. Ciência da Informação, v. 33, n. 3, p. 35-40, 2004.

Gasque, K. C. G. D.; Tescarolo, R. Desafios para implementar o letramento informacional na educação básica. Educação em Revista, v. 26, n. 1, p. 41-56, 2010.

Gatti, B. A. Análise das políticas públicas para formação continuada no Brasil, na última década. Revista Brasileira de Educação, v. 13, n. 37, p. 57-70, 2008.

Gomes, S.; Fialho, J.; Silva, E. C. Competência em informação de agentes envolvidos no Ensino a Distância da Universidade Federal de Goiás - Brasil. Revista Interamericana de Bibliotecología, v. 36, n. 1, p.47-62, 2013.

Heather, N.; Nicole, E. Information literacy instruction for satellite university students. Reference Services Review, v. 39, n. 3, p. 497-513, 2011.

Kilic-Cakmak, E. Learning strategies and motivational factors predicting information literacy self-efficacy of e-learners. Australasian Journal of Educational Technology, v. 2, n. 2, p. 192-208, 2010.
Kovalik, C.; Yutzey, S.; Piazza, L. Information literacy and high school seniors: Perceptions of the research process. School Library Research, v. 65, n. 1, p. 55-56, 2013.

Kratochvil, J. Evaluation of e-learning course, Information Literacy, for medical students. Electronic Library, v. 31, n. 1, p. 55-69, 2013.

Le Coadic, Y-F. A Ciência da Informação. Brasília: Briquet de Lemos, 2004.

Martins, O. B. Os caminhos da EAD no Brasil. Revista Diálogo Educacional, v. 8, n. 24, p. 357-371, 2008.

Mata, M. L.; Casarin, H. C. S. Inserção de conteúdo de competência informacional e de formação pedagógica nos currículos dos cursos de Biblioteconomia do Brasil: uma análise por meio dos sites institucionais. In: Encontro Nacional de Pesquisa em Ciência da Informação, 13., 2012, Rio de Janeiro. Anais... Rio de Janeiro: Fiocruz, 2012.

Moran, J. M. Ensino e aprendizagem inovadores com tecnologias. Informática na educação: Teoria e Prática, v.3, n. 1, p. 137-144, 2000.

Mota, F. R. L. Competência informacional e necessidade de interação entre bibliotecários e professores no contexto escolar. Informação e Sociedade: Estudos, v. 16, n. 1, p. 121-127, 2006.

Mueller, S. P. M. Perfil do Bibliotecário, serviços e responsabilidades na área de informação e formação profissional. Revista de Biblioteconomia de Brasília, v. 17, n. 1, p. 63-70, 1989.

Nazari, M. A contextual model of information literacy. Journal of Information Science, v. 37, n. 4, p. 345-359, 2011.

Nazari, M.; Webber, S. Loss of faith in the origins of information literacy in e-environments: Proposal of a holistic approach. Journal of Librarianship and Information Science, v. 44, n. 2, p. 97-107, 2012.

Orelo, E. R. M.; Vitorino, E. V. Competência informacional: um olhar para a dimensão estética. Perspectivas em Ciência da Informação, v. 17, n. 4, p. 41-56, 2012.

Pozo, J. I. Sociedade da aprendizagem e o desafio de converter informação em conhecimento. Revista Pátio, v. 8, p. 34-36, 2004. Disponível em: <http://www.udemo.org.br/A\%20 sociedade.pdf>. Acesso em: 4 ago. 2014.

Rios, T. A. Compreender e ensinar: por uma docência da melhor qualidade. 8. ed. São Paulo: Cortez, 2010.

Rios, T. A. Ética e competência. 20. ed. São Paulo: Cortez, 2011.

Santos, T. F. Competência informacional no ensino superior: um estudo de discentes de graduação em biblioteconomia no estado de Goiás. 2011. 148 f. Dissertação (Mestrado em Ciência da Informação) - Universidade de Brasília, Brasília, 2011.

Smith, J. K. Secondary teachers and information literacy (IL): Teacher understanding and perceptions of $\mathrm{IL}$ in the classroom. Library and information Science Research, v. 35, n. 3, p. 216-222, 2013.

Sousa, R. S. C.; Nascimento, B. S. N. Competências Informacionais: uma análise focada no currículo e na produção docente dos cursos de biblioteconomia e gestão da informação. Revista ACB: Biblioteconomia em Santa Catarina, v. 15, n. 2, p. 130-150, 2010. 
Tang, Y.; Tseng, H. W. Distance learners' self-efficacy and information literacy skills. The Journal of Academic Librarianship, v. 39, n. 6, p. 517-521, 2013.

Tang, Y. Distance education librarians in the United States: A study of job announcements. The Journal of Academic Librarianship, v. 39, n. 6, p. 500-505, 2013.

Van De Vord, R. Distance students and online research: Promoting information literacy through media literacy. Internet and Higher Education, v. 13, n. 3, p. 170-175, 2010.

Varlejs, J.; Stec, E.; Kwon, H. Factors affecting students' information literacy as they transition from high school to college. School Library Research, v. 17, p. 1-23, 2014.
Vitorino, E. V. A formação contínua do profissional da informação: princípios epistemológicos à competência informacional. In: Encontro Nacional de Pesquisa em Ciência da Informação, 9., 2008, São Paulo. Anais... São Paulo: USP, 2008. p. 1-15.

Vitorino, E. V. Princípios epistemológicos à competência informacional do profissional da informação. In: Congreso Isko España, 9., 2009, Valencia. Anais... Valencia: Universidad Politécnica de Valencia, 2009. p. 48-69.

Vitorino, E. V.; Piantola, D. Dimensões da competência informacional. Ciência da Informação, v. 40, n. 1, p. 99-110, 2011. Disponível em: <http://www.scielo.br/pdf/ci/v40n1/ a08v40n1.pdf>. Acesso em: 24 out. 2017. 